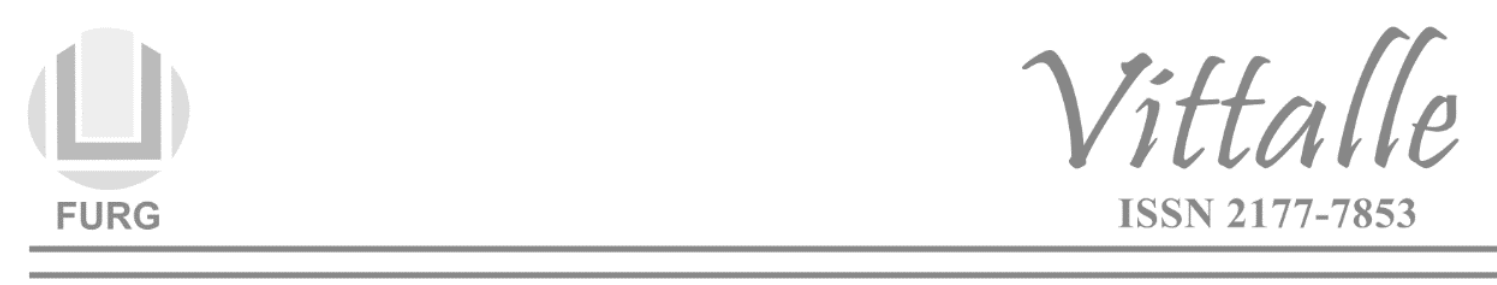

\title{
Comunicação das incertezas científicas: estratégias para a pandemia de COVID-19
}

\author{
Tatiana Pereira das Neves Gamarra*
}

Agência Nacional de Saúde Suplementar, Rio de Janeiro, RJ, Brasil

\section{Histórico:}

Recebido em:

16/05/2021

Aceito em:

$14 / 06 / 2021$

Palavras-chave:

Incerteza; comunicação;
\end{abstract} COVID-19; pandemia.

Keywords:
Uncertainty;
communication;
COVID-19; pandemics.

Modelos científicos reduzem fenômenos complexos em aproximações simplificadas que informam os formuladores de políticas sobre a probabilidade de eventos futuros. Desde a economia ao clima e ao contágio de doenças, os formuladores de políticas precisam de previsões para ponderar compensações entre custo, benefício e risco, alocar recursos e oferecer orientação aos cidadãos sobre como garantir seu bem-estar. Apesar do valor dos modelos, eles são necessariamente imperfeitos e elaborados com base em dados incompletos, variáveis ausentes e incerteza sobre a relação entre causa, efeito e as interações entre os dois. Os cientistas entendem as incertezas existentes nos modelos, mas, por causa dos desafios da saúde pública, os modelos ocuparam o centro do discurso público na pandemia de COVID-19, com elites políticas e mídia comunicando evidências científicas incertas para o público. As inevitáveis reversões nas recomendações científicas constituem outra manifestação de incerteza subjacente vulnerável à contestação. A velocidade com que a pandemia espalhou-se pelo mundo desencadeou uma corrida internacional para compreender o vírus e encontrar modos de o combater. Os pesquisadores responderam com estudos e descobertas dentro de dias e semanas, em vez dos meses ou anos habituais. O resultado inevitável foi que o "consenso" científico mudou

\footnotetext{
* Autor correspondente: tatibiom@yahoo.com.br (Gamarra T. P. N.)
} 
conforme novos dados surgiam, apresentando desafios aos formuladores de políticas que tentam ao mesmo tempo elaborar medidas de saúde pública e fornecer orientações claras e consistentes para os cidadãos (1).

Nesse contexto, um dos grandes desafios tem sido como comunicar de modo adequado, para autoridades e sociedade em geral, as incertezas relacionadas ao conhecimento científico existente e necessário para a tomada de decisões. Em uma situação assim, antes da explicitação das incertezas, faz-se necessário avaliar a qualidade das evidências apresentadas, nesse sentido, Hansson (2) propõe uma interessante sistematização de critérios para identificar e eliminar a pseudociência: crença na autoridade, experimentos que não podem ser repetidos, exemplos escolhidos de modo proposital, dificuldade para testar modelos, desconsideração de informações que refutam uma teoria, elaboração no subterfúgio e explicações razoáveis são abandonadas sem subsituição.

Depois dessa identificação do é ou não científico, é importante reconhecer que há quatro dimensões nas incertezas relacionadas às evidências científicas: técnica (inexatidão), metodológica (não confiança), epistemológica (na fronteira com a ignorância) e social (robustez social limitada). Nessa direção, um importante instrumento para auxiliar na comunicação das incertezas consiste no quadro de explicitação de suas dimensões (3).

\begin{tabular}{|c|c|c|}
\hline Dimensão & Tipo & Pode derivar de ou ser produzida por \\
\hline Técnica & Inexatidão & $\begin{array}{l}\text { Incerteza intrínseca: variabilidade, estocasticidade (origem } \\
\text { em eventos aleatórios), heterogeneidade. } \\
\text { Limitações técnicas: barras de erro, intervalos, variância; } \\
\text { erro de resolução (espacial, temporal), erro de agregação, } \\
\text { imprecisão linguística, definições pouco claras. }\end{array}$ \\
\hline Metodológica & Não confiança & $\begin{array}{l}\text { Força interna limitada da base de conhecimento: uso de } \\
\text { aproximações na base empírica e na compreensão teórica. } \\
\text { Rigor metodológico (incluindo gerenciamento de erros). } \\
\text { Validação }\end{array}$ \\
\hline Epistemológica & Ignorância & $\begin{array}{l}\text { Compreensão teórica limitada. } \\
\text { Indeterminação do sistema: abertura do sistema em estudo. } \\
\text { Comportamento caótico. Incognoscibilidade intrínseca com } \\
\text { ignorância ativa: o modelo corrige por razões compreendidas. } \\
\text { Domínio limitado da validade das suposições. Domínios } \\
\text { limitados de aplicabilidade das relações funcionais. Erro } \\
\text { numérico. Surpresas tipo A (existe alguma consciência da } \\
\text { possibilidade). Incognoscibilidade intrínseca com ignorância } \\
\text { passiva: Bugs (erro de software, erro de hardware, erros de } \\
\text { digitação). Correções de modelo por motivos não } \\
\text { compreendidos. } \\
\text { Surpresas tipo B (sem consciência da possibilidade) }\end{array}$ \\
\hline Social & $\begin{array}{c}\text { Robustez } \\
\text { social limitada }\end{array}$ & $\begin{array}{l}\text { Força externa limitada da base de conhecimento: } \\
\text { Completude do conjunto de aspectos relevantes. } \\
\text { Exploração de enquadramentos de problemas opostos. } \\
\text { Gestão da dissidência. Aceitação de pares ampliada / partes } \\
\text { interessadas } \\
\text { Envolvimento. Transparência. Acessibilidade.Viés/valores } \\
\text { envolvidos: premissas permeadas de valores axiológicos. } \\
\text { Viés motivacional (interesses, incentivos). Viés } \\
\text { disciplinar. Viés cultural. Escolha de abordagem } \\
\text { (modelagem) por exemplo, ascendente ou descendente. } \\
\text { Julgamento subjetivo. }\end{array}$ \\
\hline
\end{tabular}

Fonte: adaptado de Van der Sluijs JP (3) 
Embora tudo seja ainda recente em relação à COVID-19 e as descobertas nesta área de interface saúde/comunicação de risco ainda sejam limitadas, Paek e Hove (4) oferecem as seguintes sugestões práticas, com base nas melhores evidências disponíveis, para comunicar de forma efetiva as incertezas relacionadas ao conhecimento cietífico no contexto da pandemia:

- Quando há lacunas de conhecimento e informação, deve se dizer claramente o que se sabe e o que não se sabe atualmente.

- Ao comunicar a incerteza, explique as ações que estão sendo tomadas para reduzi-la e forneça ao público as melhores diretrizes disponíveis para ações preventivas.

- Quando há falta de consenso científico e especializado, deve haver pelo menos alguma convergência de opinião antes que as opiniões científicas sejam comunicadas amplamente ao público em geral.

- Quando as divergências científicas persistirem, explique os motivos e em que contextos específicos elas estão ocorrendo.

- Ao comunicar incertezas durante um período de crise, um porta-voz confiável deve falar ao público de forma consistente e regular com sinceridade, abertura e empatia.

- Para evitar que lacunas de informação sejam preenchidas por boatos, forneça informações de saúde e riscos atualmente conhecidas de forma repetida e regular. Use canais de mídia de transmissão tradicionais e canais mais diretos como redes sociais.

Além disso, deve ser ressaltado que a opinião de especialistas é relevante, mas, por definição, os especialistas tendem a se concentrar em um número limitado de fenômenos. Além disso, são frequentemente solicitadas recomendações em contextos restritos à sua especialidade e na ausência de informações sobre a uma conjuntura mais ampla. Embora tais recomendações possam basear-se em dados científicos é necessário lembrar que especialistas também são movidos por seus próprios pressupostos e valores. Dessa forma, é importante diferenciar os dados dos pressupostos e debater as ações no contexto dos resultados com base em diferentes conjecturas. A pandemia de COVID-19 destacou que a ciência possui característica processual, estando em permanente aprimoramento. Assim, é importante que qualquer discussão política que utilize evidências científicas, que invariavelmente envolvem incertezas em maior ou menor grau, ocorra em um contexto em que os pressupostos e valores sejam claramente explícitos, a amplitude dos resultados seja articulada e os vieses identificados (5).

Por fim, deve ser destacado que as posições expressas nesse artigo pertencem exclusivamente à autora e não refletem, necessariamente, a visão da instituição à qual está vinculada.

\section{Referências}

1. Kreps SE, Kriner DL. Model uncertainty, political contestation, and public trust in science: evidence from the COVID-19 pandemic. Sci Adv. 2020; 6(43): eabd4563.d

2. Hansson SO. Science and Pseudo-Science. The Stanford Encyclopedia of Philosophy. Edward N. Zalta (ed.); 2017. Disponível em: https://plato.stanford.edu/archives/sum2017/entries/pseudo-science/.

3. Van der Sluijs JP. The NUSAP approach to uncertainty appraisal and communication. In: Spash CL. Routledge Handbook of Ecological Economics. London: Routledge; 2017: 301-10.

4. Paek HJ, Hove T. Communicating uncertainties during the COVID-19 Outbreak. Health Commun. 2020; 35(14): 1729-31.

5. Stewart DW. Uncertainty and risk are multidimensional: lessons from the COVID-19 Pandemic. J Public Policy Mark. 2020; 40(1): 97-8. 